\title{
Effect of Dietary Habits and Socio-economic Status on Menstrual Disorders among Young Females
}

\author{
Jasjit Kaur Randhawa ${ }^{1, ~}$, Kapila Mahajan ${ }^{1}$, Manbir Kaur ${ }^{2}$, Arti Gupta $^{1}$ \\ ${ }^{1}$ Department of Zoology, Khalsa College, Amritsar, India \\ ${ }^{2}$ Department of Mathematics, Khalsa College for Women, Amritsar, India
}

Email address:

jaskrandhawa@gmail.com (J. K. Randhawa),kthukral1983@yahoo.co.in (K. Mahajan), manbirkaur.231@gmail.com (M. Kaur), artigupta0892@gmail.com (A. Gupta)

${ }^{*}$ Corresponding author

\section{To cite this article:}

Jasjit Kaur Randhawa, Kapila Mahajan, Manbir Kaur, Arti Gupta. Effect of Dietary Habits and Socio-economic Status on Menstrual Disorders among Young Females. American Journal of BioScience. Special Issue: Academic Research for Multidisciplinary.

Vol. 4, No. 3-1, 2016, pp. 19-22. doi: 10.11648/j.ajbio.s.2016040301.14

Received: March 26, 2016; Accepted: June 1, 2016; Published: June 30, 2016

\begin{abstract}
Menstruation is very important phase of reproductive cycle which involves many hormonal changes. Hormone production is known to be affected by diet. Poor nutrition in female diet can affect menstrual cycle and lead to menstrual disorders and pre-menstrual syndrome (PMS). A cross-sectional study was undertaken to analyze the association of dietary habits and socio-economic status with menstrual disorders among the college going and young working females of Amritsar, Punjab, India during the month of Jan-March 2013. Students who did not attain menarche; were suffering from any chronic health condition or using any medicines for long duration (more than a month) were excluded from the study. A total of 100 females were selected, among 300 surveyed, for this study and each student was given a questionnaire to complete. Majority of the females $(87 \%)$ belong to middle socio-economic status, having higher prevalence of menstrual disorders due to sedentary lifestyle and western dietary habits. Greater prevalence of menstrual disorders was observed in vegetarian women as compared to non-vegetarian women except for dysmenorrhea. Prevalence of menorrhagia was higher (56.25\% vs. $32.69 \%)$ in women not taking salad daily while percentages of menorrhagia $(44.68 \%$ vs. $43.40 \%)$ as well as oligomenorrhea $(46.81 \%$ vs. $45.28 \%)$ were found higher in women not eating fruits daily. $93 \%$ respondents took junk food and a positive association was observed between consumption of junk food and menstrual disorders.
\end{abstract}

Keywords: Menstrual Disorders, Nutritional Status, Menorrhagia, Dysmenorrhea, Oligomenorrhea, Pre-menstrual Syndrome

\section{Introduction}

Nutrition is the intake of balanced diet required for maintaining good health. Nutritive foods enable us to grow well and enjoy good health. On the other hand, poor nutrition can lead to reduced immunity, increased susceptibility to disease, impaired physical and mental development, and reduced productivity. The normal menstrual cycle in females represents the complex interplay of hormones such as estrogen and progesterone. In a healthy woman, the menstrual cycle averages 28 days in length; with a normal range of 21-35 days.

The mechanisms responsible for possible differences in the menstrual cycle include energy imbalances associated with body weight disturbances or exercise, psychosocial and cognitive factors, and components of the diet - acting singly or in combination. Although a variety of lifestyle and medical factors can affect menstruation, a poor diet is a potential cause for hormonal changes in menstrual cycle leading to menstrual disorders.

Pre-menstrual syndrome (PMS) represents set of symptoms which include physical, psychological and behavioral changes characterized by mood swings, headache, bloating, stress, anxiety, and backache. These symptoms can be worsened by consumption of caffeine, salt, sugar, alcohol and foods high in fat. Irregularity in cycle may also result from lack of proper nutrition or diets high in carbohydrates. 
Whereas heavy bleeding is mainly concerned with low progesterone level and it is generally common in those women who are anemic. It can be reduced by taking multivitamins and through certain foods such as meat, poultry and fish.

Eating a healthy diet is known to have a variety of health benefits and should be recommended to virtually all women. Dietary changes can promote regular periods. Literature reviewed revealed that non-vegetarian diet help in maintaining fairly consistent levels of estradiol and progesterone which resulted in regular menstrual cycles whereas vegetarian diet lead to considerable reductions in estradiol and progesterone. Increased fruit, vegetable and water consumption can also regulate the menstrual cycle and reduce symptoms of PMS.

\section{Materials and Methods}

The present research work intends to study the association of dietary habits and socioeconomic status with menstrual disorders among the college going and young working females of Amritsar city, Punjab, India during the month of Jan-March 2013.

\subsection{Data Collection}

The design of the study was cross sectional in nature. All subjects were invited to answer the questionnaire, which dealt with anthropometric data, socio-economic data, menstrual history, and dietary habits. The questionnaire was self-administered, semi-structured and prepared in local and English languages. Students who did not attain menarche, who are suffering from any chronic health condition and are using any medicines for long duration (more than a month) were excluded from the study. A total of 100 college going and young working females were chosen for this study and each student was given a questionnaire to complete. In the previous study, authors have revealed prevalence of menstrual disorders as well as their association with obesity [1]. In the present study, participants were classified into upper, middle or lower socioeconomic groups on the basis of Kuppuswamy's Socio-economic Status Scale [2]. For dietary details, questionnaires include questions regarding daily fruits, salad, milk, egg and junk food consumption, vegetarian and non-vegetarian diet.

\subsection{Statistical Analysis}

Prevalence of each menstrual abnormality was calculated and expressed as percentages. A relationship among dietary habits, socioeconomic status and menstrual disorders was separately assessed using Pearson's correlation coefficient. Statistical analysis was done using SPSS16 Software and $p$ value $<0.05$ was considered as statistically significant.

\section{Results and Discussion}

In the present study, age of the women selected for study was between 17-33years with a mean of 22.7years. Data on percentage of dietary habits and menstrual disorders were shown in Table 1 . Non-vegetarian dietary pattern and daily salad consumption was noticed to an extent of 52 percent. Women with daily fruits and milk consumption were 53 percent and 54 percent respectively. Self-reported prevalence of egg and junk food consumption were 62 percent and 93 percent respectively. Majority of the females (83.00\%) belong to middle socioeconomic status while only $13.00 \%$ belong to lower socio-economic status.

\subsection{Vegetarian and Non-vegetarian Diet}

In the present study, prevalence of menstrual disorders was increased in vegetarian women as compared to nonvegetarian women except for dysmenorrhea. According to Barr [3], three general mechanisms contributing menstrual disturbances between vegetarians and non-vegetarians include energy imbalances associated with body-weight disturbances or exercise, psychosocial and cognitive factors, and dietary components. Literature reviewed revealed that strictly vegetarian diet may lead to deficiencies of vit. B12, calcium, iron, zinc etc. whereas vegetarian diet including with dairy products and vitamin-mineral supplements reduced the risk of nutritional deficiencies and growth impairment. According to Sharma et al. [4] the hemoglobin levels of non-vegetarianism were high in obese women than vegetarian.

Table 1. Percentages of menstrual disorders with respect to various dietary habits.

\begin{tabular}{|c|c|c|c|c|c|c|c|c|c|c|c|c|}
\hline \multirow{2}{*}{$\begin{array}{l}\text { Menstrual } \\
\text { Disorder }\end{array}$} & \multicolumn{2}{|c|}{ Non veg } & \multicolumn{2}{|l|}{ Salad } & \multicolumn{2}{|l|}{ Fruits } & \multicolumn{2}{|l|}{ Milk } & \multicolumn{2}{|l|}{ Egg } & \multicolumn{2}{|c|}{ Junk food } \\
\hline & $\begin{array}{l}\text { Yes } \\
(n=52)\end{array}$ & $\begin{array}{l}\text { No } \\
(n=48)\end{array}$ & $\begin{array}{l}\text { Yes } \\
(n=52)\end{array}$ & $\begin{array}{l}\text { No } \\
(n=48)\end{array}$ & $\begin{array}{l}\text { Yes } \\
(n=53)\end{array}$ & $\begin{array}{l}\text { No } \\
(n=47)\end{array}$ & $\begin{array}{l}\text { Yes } \\
(n=54)\end{array}$ & $\begin{array}{l}\text { No } \\
(n=46)\end{array}$ & $\begin{array}{l}\text { Yes } \\
(n=62)\end{array}$ & $\begin{array}{l}\text { No } \\
(n=38)\end{array}$ & $\begin{array}{l}\text { Yes } \\
(n=93)\end{array}$ & $\begin{array}{l}\text { No } \\
(n=07)\end{array}$ \\
\hline Dysmenorrhea & 34.62 & 77.08 & 73.08 & 62.50 & 67.92 & 68.09 & 64.81 & 71.74 & 62.90 & 74.36 & 68.82 & 57.14 \\
\hline Menorrhagia & 19.23 & 41.67 & 32.69 & 56.25 & 43.40 & 44.68 & 50.00 & 36.96 & 46.77 & 38.46 & 46.24 & 14.29 \\
\hline Metorrhagia & 9.62 & 12.50 & 15.38 & 6.25 & 13.21 & 8.51 & 11.11 & 10.87 & 9.68 & 12.82 & 10.75 & 14.29 \\
\hline Oligomenorrhea & 21.15 & 45.83 & 51.92 & 39.58 & 45.28 & 46.81 & 38.89 & 54.35 & 43.55 & 48.72 & 44.09 & 71.43 \\
\hline
\end{tabular}

\subsection{Fruits and Salad}

Prevalence of menorrhagia was observed to be higher in women not taking salad daily while percentages of menorrhagia as well as oligomenorrhea were found higher in women not eating fruits daily. Fruits and vegetables are rich sources of antioxidants, including vitamins $\mathrm{C}$ and $\mathrm{E}$, carotenoids and flavonoids, as well as numerous other phytochemicals. Both of these are low calorie food help in maintaining healthy body weight. Fewer intakes of fruits and vegetables may lead to obesity and oxidative stress 
implicated in menstrual problems and infertility $[5,6]$.

\subsection{Milk}

The results of the present study revealed that percentages of dysmenorrhea and oligomenorrhea were higher in females not taking milk daily as compared to females consuming regular milk. Milk and milk productsare good source of calcium also directly affect obesity and insulin-resistance, two factors which themselves act as the causes of hormonal imbalance in women leading to various menstrual and reproductive problems [7]. In a case-control study carried out in Al-Zahra hospital of the city of Tabriz, it was observed that the intake amounts of $\mathrm{Ca}, \mathrm{Mg}, \mathrm{D}$ vitamin, dairy, fruits and nuts and seeds were remarkably low among the women with
Polycystic ovary syndrome[8]. Pereira et al. [9] found an inverse relationship between consuming more than 4 units of dairy products per day and metabolic syndrome in the females.

\section{4. $\mathrm{Egg}$}

In the present study, prevalence of menstrual disorders i.e. dysmenorrhea, metorrhagia and oligomenorrhea was higher in women on strictly vegetarian diet not including egg. Inadequate intake of protein can often affect the menstrual cycle. Optimum protein intake in the form of plant proteins like soybean, legumes and pulses; and animal protein like milk, fish, egg, meat etc. should be followed for healthy menstrual flow.

Table 2. Pearson's correlation analysis of menstrual disorders with confounding factors.

\begin{tabular}{|c|c|c|c|c|c|c|c|c|}
\hline Menstrual Disorders & & Veg/Non Veg & Salad & Fruits & Milk & Egg & Junk food & *SES \\
\hline \multirow{2}{*}{ Dysmenorrhea } & $\mathrm{r}$ & -0.187 & 0.113 & -0.002 & -0.074 & -0.109 & 0.064 & -0.082 \\
\hline & $\mathrm{p}$ & 0.062 & 0.262 & 0.986 & 0.464 & 0.280 & 0.528 & 0.416 \\
\hline \multirow{2}{*}{ Menorrhagia } & $\mathrm{r}$ & 0.045 & -0.237 & -0.013 & 0.131 & 0.089 & 0.164 & -0.189 \\
\hline & $\mathrm{p}$ & 0.655 & 0.018 & 0.899 & 0.194 & 0.377 & 0.103 & 0.050 \\
\hline \multirow{2}{*}{ Metorrhagia } & $\mathrm{r}$ & -0.046 & 0.146 & 0.075 & 0.004 & -0.047 & -0.029 & -0.011 \\
\hline & $\mathrm{p}$ & 0.649 & 0.148 & 0.459 & 0.970 & 0.646 & 0.776 & 0.913 \\
\hline Oligomenorrhea & $\mathrm{p}$ & 0.975 & 0.220 & 0.880 & 0.125 & 0.667 & 0.165 & 0.042 \\
\hline
\end{tabular}

r- Correlation coefficient, p- significance level

*SES- Socio-economic status

\subsection{Junk Food}

In the study we noticed that $93.00 \%$ respondents took junk food and association was observed between consumption of junk food and menstrual disorders. In a study by Rupavani et al. [10], Junk foods being deficient in micronutrients like vitamin B6, calcium, magnesium and potassium might be responsible for triggering premenstrual symptoms. Another study by Nirmala et al. [11] reported a significant association between irregular menstrual cycles, abnormal flow, dysmenorrhea and PMS with frequent consumption of junk food. As per Fujiwara et al. [12] Frequency of fast food intake was significantly associated with dysmenorrhea. According to Lakshmi [13], decreasing the intake of junk foods and promoting healthy eating habits should be emphasized to improve menstrual health of young college students.

\subsection{Socio-economic Status}

Lower socio-economic status was found to be associated with greater disease severity, greater morbidity, higher mortality and higher barriers to access to more advance medical services in the previous studies [14-16]. However, as in the present study the prevalence of menstrual disorders was more in females with middle socio-economic status due to sedentary lifestyle and consumption of junk food as compared to low socio-economic status.

On Pearson's correlation analysis, significant negative association of menorrhagia was observed with salad consumption and socioeconomic status, while positive association was observed between oligomenorrhea and socioeconomic status. The association with socioeconomic status was conflicting may be due to more consumption of junk food, sedentary lifestyle and unawareness about nutritious diet in individuals with high socioeconomic status.

\section{Conclusion}

Menstrual disorders like dysmenorrhea, menorrhagia, metorrhagia, oligomenorrhea and premenstrual syndrome were very common among young females of middle socioeconomic status as compared to low socio-economic status. Dietary habits like salad consumption, fruits intake, vegetarian/non vegetarian preferences etc. were observed to be influencing the prevalence of metabolic disorder. Based on the findings of this study, it can be concluded that healthy dietary pattern and socio-economic status are positive contributors to menstrual disorders. This provides additional evidence that a regular menstruation phenomenon is affected by the dietary quality and the nutritional status of the females.

\section{References}

[1] J.K. Randhawa, K. Mahajan and A. Gupta (2016) Menstrual disorders among young females of Amritsar. J. Exp. Zool. India 19(1): 401-403.

[2] B. Kuppuswamy (1981) Manual of Socioeconomic Status (Urban). Delhi: Manasayan. 
[3] S.I. Barr (1999) Vegetarianism and menstrual cycle disturbances: is there an association? Am. J. Clin. Nutr.70(suppl): 549S-554S.

[4] S.V. Sharma, S. Koonwar, V. Atam, U. Singh, M.L. Patel (2013) Study of hemoglobin in vegetarian and non- vegetarian diet in obese women with risk of cardiac problem in Lucknow city. NJMR 3(2): 170-172.

[5] S.M. Rink, P. Mendola, S.L. Mumford, J.K. Poudrier, R.W. Browne, J. Wactawski-Wende, N.J. Perkins, E.F. Schisterman (2013) Self-report of fruit and vegetable intake that meets the 5 a day recommendation is associated with reduced levels of oxidative stress biomarkers and increased levels of antioxidant defense in premenopausal women. J. Acad. Nutr. Diet. 113(6):776-85.

[6] A. Brevik, I. Gaivao, T. Medin, A. Jorgenesen, A. Piasek, J. Elilasson, A. Karlsen, R. Blomhoff, T. Veggan, A.K. Duttaroy AK, et al. (2011) Supplementation of a western diet with golden kiwifruits (Actinidiachinensisvar.'Hort 16A':) effects on biomarkers of oxidation damage and antioxidant protection. Nutr. J. 10: 54.

[7] B.J Billaudel, P.M. Bourlon, B.C Sutter, A.G. Faure-Dussert (1995) Regulatory effect of 1,25-dihydroxyvitamin D3 on insulin release and calcium handling via the phospholipid pathway in islets from vitamin D-deficient rats. J. Endocrinol. Invest. 18:673-682.

[8] G. Rajaeieh, M. Marasi, Z. Shahshahan, F. Hassanbeigi, S.M. Safavi (2014) Therelationship between intake of dairy products and polycystic ovary syndrome in women who referred to Isfahan University of Medical Science clinics in 2013. Int. J. Prev. Med. 5(6): 687-694.

[9] M.A. Pereira, D.R. Jacobs, L. Van Horn, M.L. Slattery, A.I.
Kartashov, D.S. Ludwig (2002) Dairy consumption, obesity, and the insulin resistance syndrome in young adults: The CARDIA Study. JAMA. 287:2081-2089.

[10] K. RupaVani, K.S. Veena, L. Subitha, V.R. Hemanthkumar, A. Bupathy (2013) Menstrual abnormalities in school going girls - Are they related to Dietary and Exercise pattern? J. Clin. Diagn. Res. 7(11): 2537-2540.

[11] J.L. Nirmala, R.L. Jaya Vani, P. NivedhanaAarthi, P. Alaganandam, N. Vanajakshi (2014) A study of menstrual disorders in medical students and its correlation with Biological variables Sch. J. App. Med. Sci. 2 (6): 3165-3175.

[12] T. Fujiwara, N. Sato, H. Awaji, H. Sakamata, R. Nakata (2009) Skipping breakfast adversely affects menstrual disorders in young college students. Int. J. Food Sci. Nutr. 60(6): 23-31.

[13] S. Audhi Lakshmi (2015) Impact of life style and dietary habits on menstrual cycle of college students. International Journal of Science and Research 4(4): 2845-2847.

[14] C.K. Landy, W. Sword, D. Ciliska (2008) Urban women's socioeconomic status, health service needs and utilization in the four weeks after postpartum hospital discharge: findings of a Canadian cross-sectional survey. BMC Health Serv. Res. 8:203.

[15] T.S. Yu, T.W. Wong (2004) Socioeconomic distribution of health and health care utilization in a new town in Hong Kong, China. Biomed. Environ. Sci. 17:234-245.

[16] J. Woo, E. Lau, C.S. Lau, P. Lee, J. Zhang, T. Kwok, C. Chan, P. Chiu, K.M. Chan, A. Chan, D. Lam (2003) Socioeconomic impact of osteoarthritis in Hong Kong: utilization of health and social services, and direct and indirect costs. Arthritis Rheum. 49:526-534. 